\title{
COAGULACION LACTEA INDUCIDA POR ENZIMAS DE CUAJO DE LLAMA (Lama glama)
}

\author{
Dániza M. Guerrero Alva ${ }^{1}$
}

\author{
RESUMEN
}

Cuajo, quimosina o zimasa son algunos de los nombres con los que se designa a las enzimas provenientes del estómago de terneros y ovejas de pocos dias de nacidos y que se emplean para coagular la leche. En nuestro pais, los campesinos delas zonas andinas utilizan el cuajo de llama para el mismo propósito.

Por tal motivo, se desarrolló el estudio del macerado (D. O. de 0.15 a $350 \mathrm{~nm}$ ), para evaluar su potencialidad mediante el conocimiento de sus características.

Para ello se determinó el poder coagulante del mismo de acuerdo a la técnica de Berridge, correspondiente a 22018, clasificando el producto como un Extracto.

La actividad enzimática hallada en términos de Unidades de Actividad Coagulante correspondió a 16383 U.A.C.

La hidrólisis de la kappa caseina por acción de las enzimas del extracto de llama produjo péptidos solubles en ácido tricloro acético al $3 \%$ con una tasa constante de reacción de $3,3 \times 10^{+4} \mathrm{~s}^{\prime}$, llegandose a la máxima formación transcurridos los veinticuatro minutos iniciales. Por otro lado, la fase secundaria del proceso de coagulación caracterizada por la formación de agregados de para-kappa-caseina tuvo una tasa de 2,48 $\times 10^{3} \mathrm{~s}^{\prime}$. El efecto promotor e inhibidor de la fracción alfa sobre kappa daseina también fue estudiada, determinándose nuevas tasas de reacción.

Además, al incrementar o disminuir la concentración del sustrato respecto a la concentración estandar; no varió el tiempo de coagulación, no asi a bajas concentraciones en las que predomina la reacción de hidrólisis de la caseina por no llegar a insolubilizarse el paracaseinato. Con respecto al pH, se comprobo el efecto inverso sobre el tiempo de coagulación en el rango de 6,5 a 7,2.

\section{INTRODUCCION}

El fenómeno de coagulación de la leche puede desarrollarse por actividad enzimática o por adición de ácidos. En el primer caso el agente coagulante es el cuajo, extracto enzimático proveniente del cuarto estómago de los rumiantes mamones obtenido por maceración de los mismos, generalmente terneros, cabritos u ovejas.

En las zonas andinas del país la tecnología

1. Ingeniero en industrias alimentarias tradicional hace uso del cuajo de llama con el mismo propósito que las provenientes de factura industrial.

Se desconoce desde cuándo el poblador andino empezó a usar la técnica de extracción enzimática del cuajo de llama, pero, sin duda,existe un paralelismo entre el tratamiento del cuajar de llama y el de cabrito usado en Europa; aunque la eficiencia de la solución extrayente y su composición son características y típicas de nuestro país.

Por otro lado, la crianza de llamas por los pobladores andinos está completamente sistematizada 
conla finalidad de lograrsu perfeccionamiento yutilización total: poblador de la sierra ha logrado incorporar a la vida económica y al sistema alimenticio la carne rica en proteínas; su fibra usada para confeccionar tejidos, sogas, aperos y demás; la grasa que, de acuerdo a su punto de fusión, la aplican como ungüento, en comidas, en la fabricación de velas y jabones o en los "pagos"; el cuero, para hacer hojotas y sogas resistentes; el estiércol, como abono, y el cuajo para preparar quesos. Además, es ampliamente conocido el uso de la llama como animal de carga.

Como se sabe, las proteinasas, denominadas también proteasas ó enzimas proteolíticas, son las más importantes para el procesamiento de alimentos: en la industria cárnica, para la modificación de las propiedades de la proteína del trigo destinado a la manufactura del pan , en la fabricación de cerveza y en la industria quesera al desestabilizar el sistema micelar lácteo para producir un gel por hidrólisis proteica.

La clasificación de las enzimas proteolíticas puede hacerse en dos grandes grupos: las endopeptidasas si atacan las uniones peptídicas a lo largo de la cadena, y las exopeptidasas que hidrolizan uniones peptídicas adyacentes a los grupos terminales aminos o carboxilos, originando aminoácidos individuales.

Hartley (en 1960 citado por Whitaker 1972) ha sugerido una subdivisión de las enzimas proteolíticas en cuatro grupos, de acuerdo a su mecanismo de acción:

a) Proteasas séricas.- inhibidas por el diisopropil-pfluoridato (DFP) que reacciona con un grupo hidroxilo de un residuo serílico específico en el sitio activo de la enzimas. Todas estas enzimas son endopeptidasas y parecen tener un grupo imidazol en el sitio activo; siendo las especificidades de substrato totalmente diferentes para las enzimas comprendidas en la subclasificación, (cuadro Nro. 1)

CUADRONo.1: Especificidad de sustrato para algunas proteasas séricas.

\begin{tabular}{|ll|}
\hline \multicolumn{1}{|c|}{ ENZIMA } & \multicolumn{1}{c|}{ ESPECIFICIDAD } \\
\hline a-Quimotripsina, bovina & Tirosina, Fenilalanina, Triptofano \\
Quimotripsina B, bovina & Tirosina, Fenilalanina, Triptofano \\
Tripsina B, bovina & Lisina, Arginina \\
Trombina, bovina & Lisina, Arginina \\
Elastina, bovina & Alanina \\
Subtilisina, B. subtilis calsberg. & Tirosina, Fenilalanina, Triptofano \\
\hline
\end{tabular}

FUENTE: WHITAKERJ., 1972

b) Proteasas sulfidrílicas.- este grupo de enzimas hidrolizan los enlaces peptídicos de las proteínas siendo inhibidas por agentes sulfidrílicos. Involucra a la mayoría de enzimas de origen vegetal como papaína, bromelina y ficina, así como las microbianas, por ejemplo Streptococcus peptidasa.

c) Proteasas que contienen metales .- son en su mayoría exopeptidasas que requieren para su actuación la presencia de iones divalentes como manganeso y zinc.

d) Proteasas ácidas.- se les denomina así porque el $\mathrm{pH}$ óptimo es muy bajo ( 2 para la pepsina y 4 para otras proteasas ácidas), que indicaría la existencia de uno o más grupos carboxilo presentes en el sitio activo. La enzima más estudiada de este grupo es la pepsina, pero la renina posee el mayor uso comercial debido a su utilización en la manufactura de quesos. En el cuadro No. 2 se citan las enzimas más representativas que conforman la subdivisión de las proteasas, considerándose que tanto las proteasas ácidas (renina y pepsina) así como las séricas (quimosina y tripsina) tienen acción directa en la fabricación de quesos frescos y madurados.

CUADRO No. 2: Subdivisión de las enzimas proteolíticas.

\begin{tabular}{|ll|}
\hline SUBDIVISION & ENZIMASMASREPRESENTATIVAS \\
\hline 1. Proteínas Séricas & Quimotripsina A (a, d, n, ) \\
& Tripsina \\
& Elastina \\
& Trombina \\
& Subtilisina \\
2.- Proteasas Sulfidrilicas & a-Proteasa lítica \\
& Papaina \\
& Ficina \\
& Bromelina \\
3.- Proteasas que contienen metal & Streptococcus peptidasa \\
& Carboxipeptidasas A \\
& Glicil-glicina-peptidasa \\
& Carnosinasa \\
4.- Proteasas Acidas & Leucin aminopeptidasa \\
& Iminodipeptidasa \\
& Pepsina \\
& Renina \\
\hline
\end{tabular}

\section{CUAJO, RENINA O LAB}

Con el nombre de cuajo se suele designar a la enzima proteolítica secretada por el cuarto estómago de los rumiantes antes del destete como pro-cuajo A y B (zimógenos) que mediante un proceso autocatalítico acelerado por los iones hidronio se convierten en su forma 
activa. El punto isoeléctrico de la enzima sin actividad es de 5 pero en la forma activada desciende a 4,7 por la separación de los péptidos ricos en tirosina presentes en elN-terminal. La secreción de esta enzima en el estómago de los bovinos o cabritos termina cuando se incorpora alimento sólido a la ración (pastos, granos, etc), siendo reemplazada por la pepsina.

El peso molecular del cuajo es cercano a 40000 y su forma cristalina posee $15 \%$ de nitrógeno muy sensiblea las variaciones de $\mathrm{pH}$, concervando suactividad proteolítica en medio ácido, aunque a pH menores de 4,8 es muy poco estable.

Whitaker denomina a la enzima secretada porel cuarto estómago de estos animales como renina, considerando el pH de máxima estabilidad la región cercana a 5 , y su desnaturalización por encima de 6 . Asimismo, reporta un peso molecular de 30000 , y la máxima actividad a pH cercano a 3,5.

\section{QUIMOTRIPSINA}

Se produce en el páncreas de los bovinos en sus formas inactivas $\mathrm{A}$ y $\mathrm{B}$ diferenciándose marcadamente en la composición de aminoácidos lo cual se refleja en la diferencia de sus puntos isoeléctricos $(8,5$ y 4,5 para $A$ y $B$ respectivamente).

El quimotripsinógeno $A$ es una cadena polipeptídica única con peso molecular de 25000 conteniendo 245 residuos de aminoácidosy 5 enlaces disulfuro; al convertirse en sus formas activas se diferencian en sus propiedades físicas, pero sus requerimientos de especificidad de sustratro son los mismos: donde la tirosina, fenilalanina y triptofano proveen el grupo carboxílico. El páncreas deporcino secreta otro zimógeno, el quimotripsinógeno $\mathrm{C}$, el cual se activa por el lado leucílico.

La conversión de quimotripsinógeno $\mathrm{A}$ en aQuimotripsina es un proceso complicado, que en términos generales se refiere a la hidrólisis de un enlace polipeptídico que deja libre a la enzima. La tripsina al actuar permite la formación de n-Quimotripsina, muy inestable y activa, constituida por dos cadenas polipeptídicas retenidas juntas por enlaces disulfuro continuándose la autólisis hacia la formación de d-Quimotripsina, para finalmente formarse aQuimotripsina, que es la forma más estable de la enzima, yestá compuesta de tres cadenas polipeptídicas unidas porenlaces disulfuro.

Son muy variadas las formas de presentación de estas enzimas en el comercio, dependiendo de las costumbres de uso de la industria lechera local, del tipo de queso, nivel industrial, costos ydisponibilidad. Funda- mentalmente se puede considerar las siguientes formas:

a) Bajo la forma de cuajares deshidratados a partir de abomasos de terneros, cabritos u otras especies.

b) Cuajos líquidos, por el empleo de la maceración en soluciones extrayentes. Poder coagulante: 1:10000.

c) Cuajos en polvo, obtenidos por deshidratación de soluciones de cuajos líquidos. Su poder coagulante oscila entre 1:100 000 y 1:150 000 .

d) Cuajo en pastillas, preparadas con gelatinay glicerina. El poder coagulante es de 1:20 000 .

Por la alta demanda de enzimas que requiere la industria quesera para la coagulación de la leche, se sigue ensayando nuevas fuentes de origen vegetal y microbiano.

En el presente trabajo, nos limitaremos al estudio de la actividad coagulante de los macerados obtenidos, por considerárseles como una alternativa para la industria quesera. Para ello ha sido necesario determinar sufuerza o poder coagulante, su especificidad enzimática; asimismo determinar la velocidad de formación de agregados de para-k-caseína y la influencia del $\mathrm{pH}$ y de la concentración de sustrato en el comportamiento del coagulante.

\section{MATERIALESY METODOS}

\subsection{MATERIALES}

Se utilizó como materia prima, el cuarto estómago de llamas extraídos de animales muertos por beneficio o por accidente, de unos días de nacidos y que hubieran sido alimentados sólo con leche, sometidos a maceración y de Densidad Optica igual a 0,15 (dilución 1:9).

Además se requirió leche en polvo descremada, reactivos, material de vidrio y Equipo correspondiente.

\subsection{METODOS}

a) Determinación de la Actividad Enzimática, Fuerza o Poder Coagulante, pormedio de la Técnica de Berridge (1945), modificada por elárea de Control de Calidad de la Cooperativa Lechera SANCOR (1982) de Argentina.

b) Efecto de la concentración en el tiempo de coagulación.

c) Efecto del pH en el tiempo de coagulación.

d) Desarrollodelaprimera fase de lacoagulación: Hidrólisis de la k-caseína usando como sustrato k-caseína obtenida por el método Swaisgood y Bruner (1962), a partir de caseína ácida mediante el método de Thompson y Kiddy (1964), y usando k-caseína. 
e) Desarrollo de la fase secundaria de la coagulación.

\section{RESULTADOSYDISCUSION}

\subsection{DETERMINACION DE LA ACTIVIDAD ENZIMÁTICA, FUERZA O PODER COAGULANTE}

Teniendo en cuenta que la Actividad Enzimática relaciona un volumen de leche susceptible de ser coagulada por un volumen de cuajo bajo ciertas condiciones de temperatura, se ha determinado el Poder Coagulante del cuajo de llama empleando la relación correspondiente a cuajos líquidos, con un resultado de 22 018. De acuerdo a la clasificación dada por Alais Ch. (1980) para cuajos comerciales, la actividad enzimática obtenida fue muy superior a los "extractos" que se utilizan en la industria quesera, con una fuerza de 1:10 000.

Al expresar el Poder Enzimático en términos de Unidades de Actividad Coagulante (U.A.C.) o Unidades Berridge se halló 16383 U.A.C.

Este valor es menor al hallado por Berridge para abomasos de ternera (50000), pero superiores a los de cordero (7 330) y cabrito (4 600), (ANIFANTAKIS Y GREEN, 1980).

\subsection{HIDROLISIS DE LA K-CASEINA}

La evaluación de la especificidad enzimática es fundamental para la fabricación de quesos por ser necesario mantener un equilibrio entre la actividad coagulante y la proteolítica. Esta última puede ser medida por la liberación de nitrógeno soluble en ácido tricloroacético o por método turbidimétrico sobre un sustrato adecuado tal como la k-caseína.

La hidrólisis de la k-caseína por acción de las enzimas extraídas del cuajo de llama, produjo péptidos solubles en ácido tricloroacético al $3 \%$ cuya formación fue evaluada por turbidimetría, llegándose a la máxima formación de péptidos transcurridos los 24 minutos iniciales (gráf. 1).

Los resultados indicarían que para las condiciones del experimento se cumple también lo postulado por CLARKE (1973) al trabajar con ácido tricloroacético al $12 \%$, que el tiempo de coagulación es inversamente proporcional a la cantidad de péptidos liberados y a la velocidad de formación de los mismos.

Graficando la absorvancia de la muestras a 620 $n m$ respecto al tiempo de reacción, resultó una ecuación de primer orden con una tasa constante de reacción de $3.3 \times 10^{-4} \mathrm{seg}^{-1}$ (gráf. 2).

No se halló una relación lineal perfecta semejante a la reportada por KATO Y ANDO (1980) utilizando ácido tricloroacético al 12\%, lo cual se analizó matemá- ticamente para las condiciones del experimento, aplicando la técnica estadística de Regresión lineal simple de la variable dependiente $Y$ (Densidad óptica) y la variable independiente $X$ (tiempo de hidrólisis de la fracción Kcaseína, en minutos), con el siguiente resultado:

$$
\mathrm{Y}=0.01950-3.000 \times 10^{-4} \times \mathrm{X}
$$

y cuyo coeficiente de correlación inverso fue de -0.4410 .

En todo caso sí se consiguió evaluar nitrógeno no proteico proveniente de la liberación por las enzimas del cuajo de llama con ácido tricloroacético al 3\%, hecho que también reportó KATO (1970) empleando renina.

Gráfico No. 1: Determinación de la liberación de nitrógeno no proteico por turbidimetría

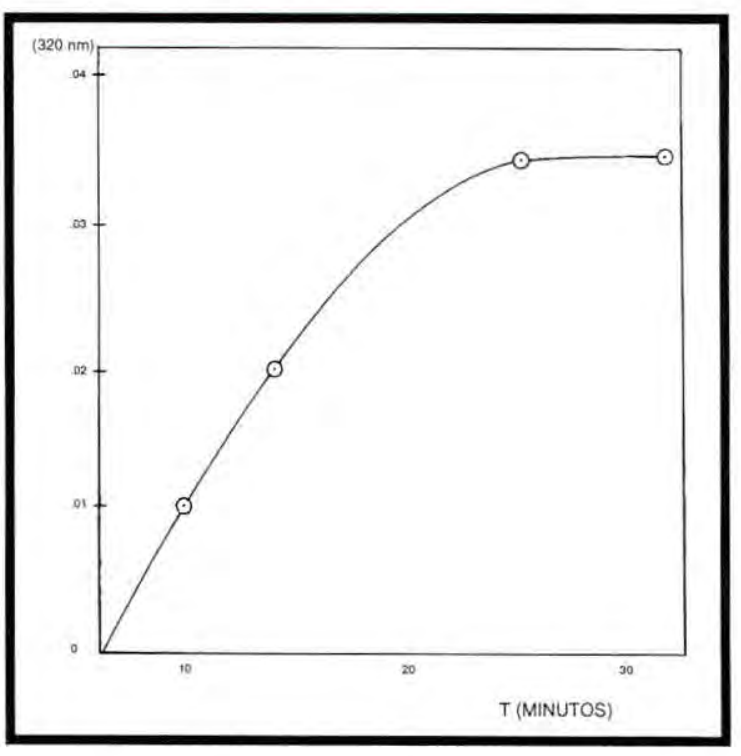

Gráfico No. 2: Expresión lineal de la liberación de nitrógeno no proteico

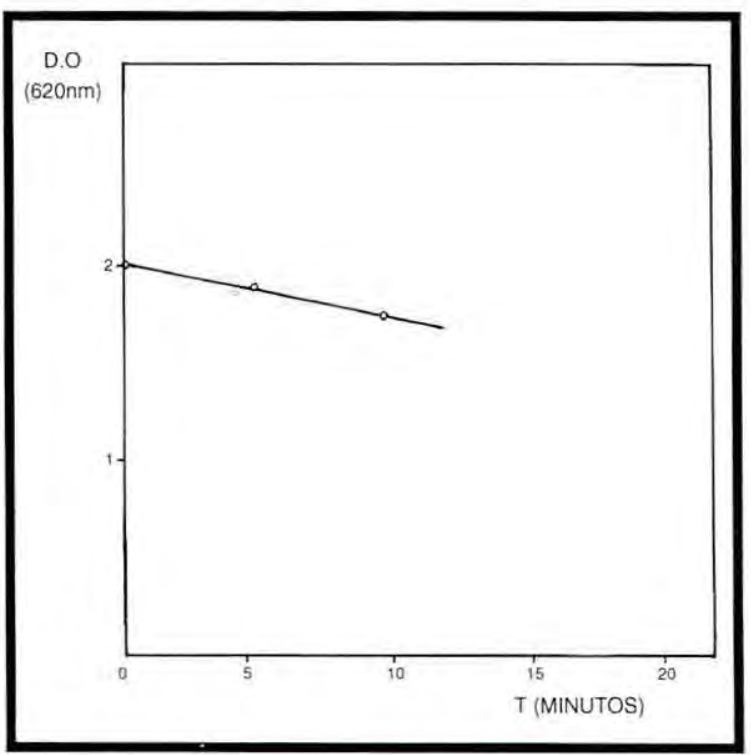




\subsection{DESARROLLO DE LA FASE SECUNDARIA DE COAGULACION}

Entre los modelos que tratan de explicar el proceso de coagulación por la renina de manera cualitativa y cuantitativa se considera los de Darling (1981), Payens (1979), Green (1981) y Dalgleish (1979). Según estas teorías el proceso está regulado inicialmente por una acción enzimática que sigue la cinética de MichaelisMenten. El proceso de agregación implica la difusión aleatoria de partículas que colisionan produciéndose uniones o repulsiones, atacando a casi la mayoría de las sustancias que proceden de la fase primaria.

En el gráfico No. 3 se presenta el desarrollo de la turbidez $\left(A_{620 \mathrm{~nm}}\right)$ debida a la formación de agregados de para-K-caseína inducidos por las enzimas del cuajo de llama, observándose que la mayor parte de la reacción tuvo lugar en los diez minutos iniciales, empleando K-caseína purificada como sustrato.

Al relacionar las lecturas de Densidad Optica respecto al tiempo se determinó un comportamiento semejante al de una pseudo ecuación de primer orden con una tasa constante de reacción de $3.16 \times 10^{-3} \mathrm{seg}^{-1}$, valor superior al reportado por KATO y ANDO (1980) correspondiente al cuajo comercial Hansen purificado $\left(2.84 \times 10^{-3} \mathrm{seg}^{-1}\right)$, no habiéndose considerado la fase inicial o lag para la determinación de la tasa de reacción (gráf. 4).

Gráfico No. 3: Desarrollo de la formación de agregados de para-K-caseína por turbidimetría

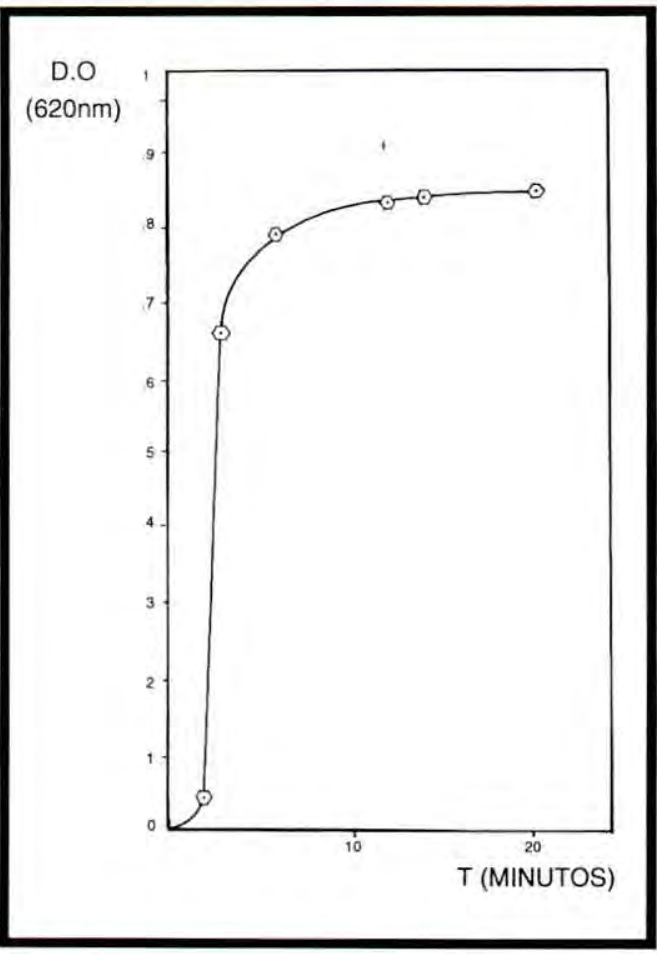

Gráfico No. 4: Expresión lineal de la formación de agregados de para-K-caseina

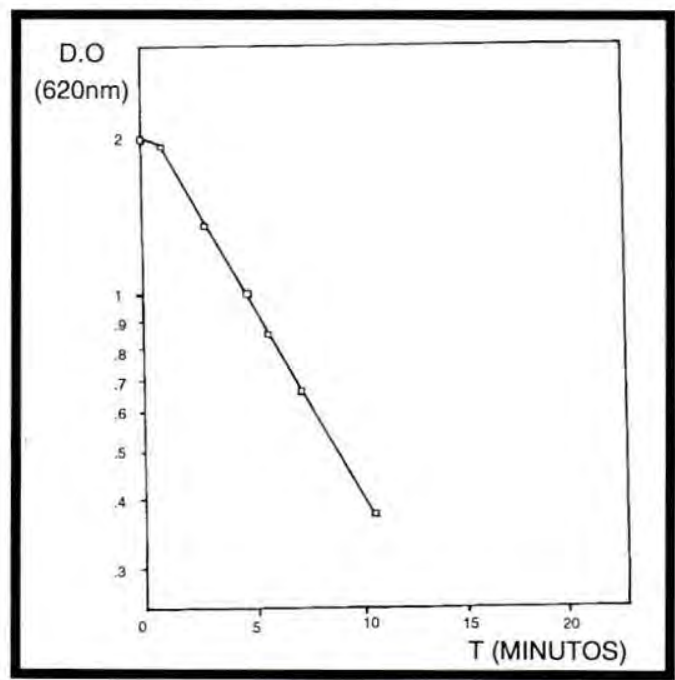

Por otrolado, se evaluó el efecto de la adición de la fracción $\propto$-caseína purificada sobre la solución de Kcaseína, empleando esta última como patrón (gráf. 5).

Gráfico No. 5: Efecto de la adición de $\propto$-caseína en la formación de agregados de para-K-caseína

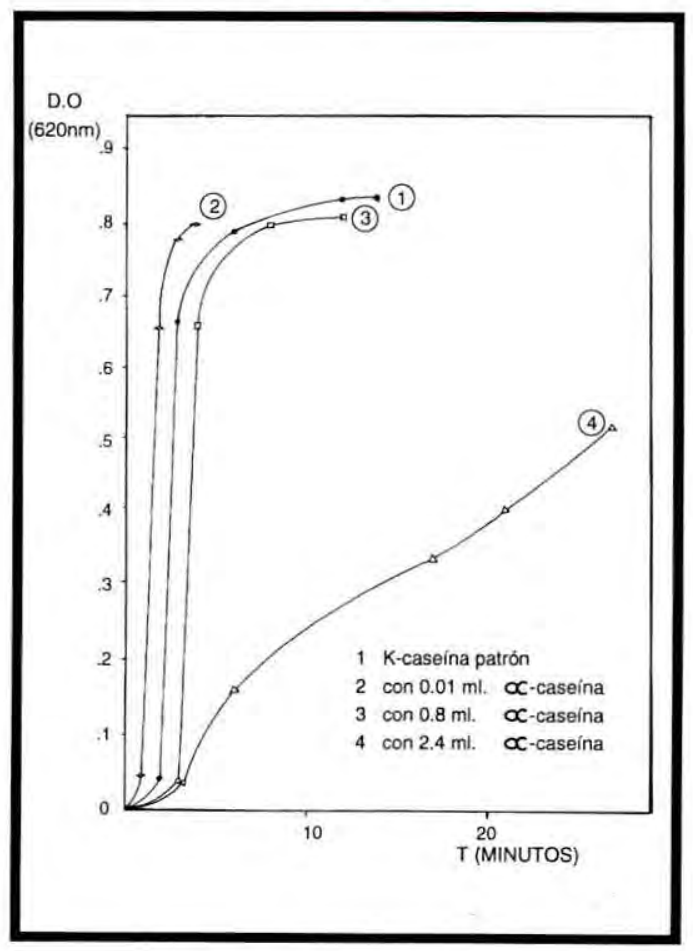

En este caso, con volúmenes pequeños de $\propto$-caseína se pudo verificar su influencia promotora en la reacción, efecto que desaparece a medida que estos volúmenes se incrementan aumentando progresivamente el tiempo que demora en producirse la turbidez.

Graficando la densidad óptica de las muestras 
respecto al tiempo se determinó las tasas resultantes para cada evaluación (cuadro 3 y gráf. 6).

CUADRO No. 3: Comparación de las Tasas de Reacción inducidas por el cuajo de llama usando las fracciones de caseína $\propto$ - y K-

\begin{tabular}{|c|c|c|c|}
\hline MUESTRA & $\begin{array}{c}\text { RELACION } \\
k-/ \propto-\text { caseina }\end{array}$ & $\mathrm{k} \times 10^{-3} \mathrm{seg}^{-1}$ & $\begin{array}{c}\text { TIEMPO QUE DEMORA EN } \\
\text { CATALIZAR } \\
\text { EL } 90 \% \text { DE LA REACCIÓN } \\
\text { (min.) }\end{array}$ \\
\hline $2^{\circ}$ & $\begin{array}{l}4 \mathrm{ml} . \mathrm{K} \text {-cas }+0,01 \mathrm{ml} . \\
\propto \text { - cas. }\end{array}$ & 4,74 & 3,0 \\
\hline$p$ & $4 \mathrm{ml} . \mathrm{K}$-cas & 3,16 & 4,5 \\
\hline $3^{\circ}$ & $\begin{array}{l}4 \mathrm{ml} . \mathrm{K} \text {-cas }+0,8 \mathrm{ml} . \\
\propto \text {-cas. }\end{array}$ & 2,37 & 5,0 \\
\hline $4^{\circ}$ & $\begin{array}{l}4 \mathrm{ml} . \mathrm{K} \text {-cas }+2,4 \mathrm{ml} . \\
\propto \text {-cas. }\end{array}$ & 0,19 & No se desarrolló \\
\hline
\end{tabular}

Gráfico No. 6: Expresión lineal del efecto de la adición de $\propto$ - caseína en la formación de agregados de para-K-caseína

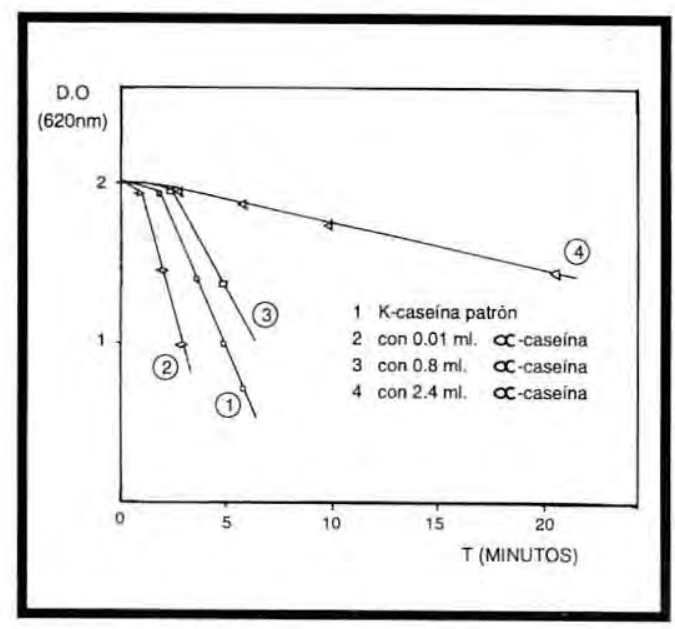

La adición de $\propto$-caseína guarda una relación directa con el tiempo que demora el producirse la reacción catalizada por las enzimas del cuajo de llama e inversa respecto de la tasa de desarrollo de la misma, semejante al comportamiento demostrado por la renina.

Payens supuso que la aceleración de la reacción de turbidez podría deberse al efecto de cargas y a los enlaces hidrofóbicos presentes, mientras que Mackenzie (1967) tratando de explicar el retardo causado por la adición de volúmenes mayores de $\propto$-caseína postula que dicha agregación es limitada por la misma K-caseína no transformada, en un mecanismo aún no establecido totalmente.

\subsection{EFECTO DEL PHEN EL TIEMPO DE COAGULA- $\mathrm{CION}$}

Otro parámetro importante para la actividad enzimática en estudio es el relativo al pH. La influencia de su variación se evaluó utilizando soluciones de buffer citrato/ácido cítrico y de buffer alcalino cloruro de calcio / hidróxido de sodio en un rango comprendido entre 6.2 y 7.5 , los cuales fueron adicionados a muestras de leche en polvo reconstituidas en una solución de cloruro de calcio al $0.05 \%$, siendo la temperatura de trabajo de $30^{\circ} \mathrm{C}$. Para cada variación de $\mathrm{pH}$ se registró el tiempo necesario para la visualización de la formación de copos caseosos.

En el gráfico 7 podemos visualizar los resultados experimentales obtenidos; así, con la adición del buffer alcalino se observó un incremento muy débil del tiempo de coagulación promovido por las enzimas del cuajo de llama hasta $\mathrm{pH} 7.2$, mientras que a pH 7.5 el tiempo de coagulación aumenta notablemente por la disminución del contenido de fosfato de calcio coloidal. Por otro lado, el efecto de la adición del buffer citrato/ácido cítrico fue de prolongar el tiempo de coagulación por solubilización del fosfato de calcio coloidal, inhibiéndose el proceso a $\mathrm{pH}$ 6.4 .

Gráfico No. 7: Efecto de la variación del pH en el tiempo de coagulación de la leche

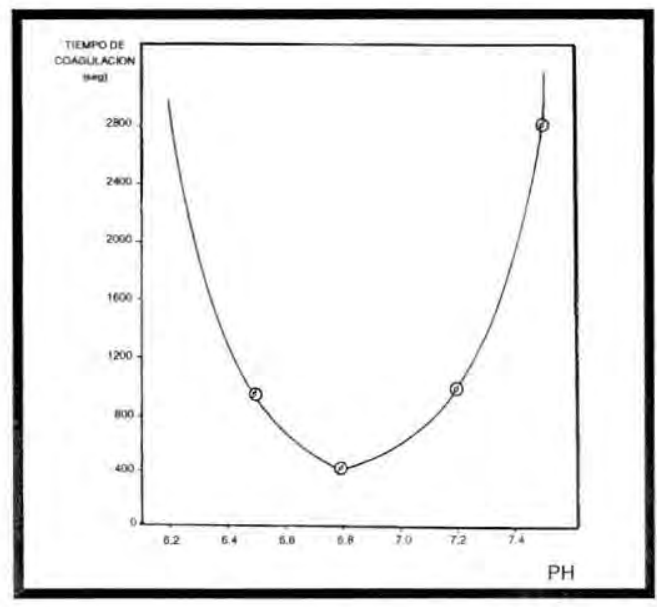

En el experimento no se inhibió la actividad enzimática a $\mathrm{pH} 6.5$, a diferencia de lo reportado por Parce en 1976 empleando renina.

Shalabiy Fox sugieren que el calcio es atrapado por el citrato permitiendo mantenerlo constante en el proceso.

Por consiguiente, a $30^{\circ} \mathrm{C}$ queda corroborado el estudio de Parce sobre el efecto inverso del pH en el tiempo coagulación usando renina y también para el cuajo de llama, pero sólo en el rango comprendido entre 6,5 y 7,2 . A pH mayores $(7,5)$ el tiempo de coagulación sufre un incremento muy considerable. 


\subsection{INFLUENCIA DE LA CONCENTRACION DE LA LECHE EN EL TIEMPO DE COAGULACION}

Para el estudio de la posible influencia de la concentración del sustrato en el tiempo de coagulación se empleó diferentes concentraciones de leche en polvo descremada y entera, mayores y menores a la que debe presentar normalmente la leche reconstituida. En todos los casos se consideró el tiempo transcurrido para la visualización de los primeros signos de coagulación por efecto de las enzimas del cuajo de llama.

En el experimento se produjo una influencia semejante a la reportada por Dalgleish (1980) con dos regiones bien definidas por la concentración estandar (4 gr. en $33 \mathrm{ml}$. de cloruro de calcio al $0.05 \%$ ); a la izquierda la zona de baja concentración y a la derecha la de alta concentración (gráf. 8).

En la región de alta concentración el tiempo de coagulación de ambas muestras presentan una tendencia promedio de 2300 seg para la leche descremada en polvo y de 800 seg para la leche entera en polvo, siendo independiente de la concentración de las muestras. A menor concentración el tiempo de coagulación se vuelve independiente e inversamente proporcional; esto se debe posiblemente a que las micelas no pueden agregarse si antes no se ha hidrolizado de manera suficiente la Kcaseína presente especialmente en la leche entera porel tamaño micelar relativamente más largo, de allí la inhibición más temprana en esa muestra.

Por consiguiente, para las concentraciones menores que la normal predomina el fenómeno de hidrólisis de la caseína o primera fase del proceso de coagulación, mientras que para concentraciones iguales o mayores a

\section{REFERENCIASBIBLIOGRAFICAS}

Anifantakis E. and Green, M. 1980. Preparation and properties of rennets from lamb's and kid's abomasa. J. Dairy Res. 47: 221-230.

Casale J., 1978. Cuajo y coagulantes de la leche. Curso Regional de quesería. FAO.

Clarke N.H., 1973. Un ensayo para la renina. Newzeland Journal of Dairy Science and Tecnolgy, 8:152.

Colowick S. and Kaplan N., 1955. Methods in Enzymology. Academic Press Inc. Pub. New York, USA.

Dalgleish D., 1979. Proteolysis and aggregation of casein micelles with immobilized or soluble chymosin. J. Dairy Res. 46.653-661.

1980. Efect of milk concentration on the rennet coagulation time. J. Dairy Res. 47,231-235.

Kato and Ando K., 1980. Action of rennin on casein. III. Efect of $\infty$-and B-casein on the secondary phase. J.
Gráfico No. 8: Influencia de la concentración de la leche en el tiempo de coagulación

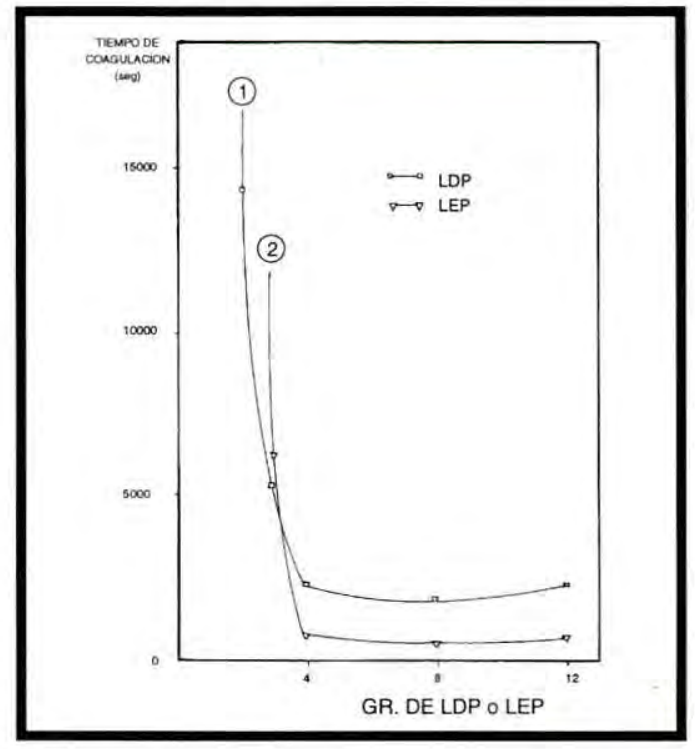

la normal, elfenómeno de agregación es el preponderante.

\section{CONCLUSION}

La investigación realizada sobre potencial enzimático del cuajo del camélido americano, llama (Lama glama), nos ha llevado a obtener resultados halagadores que permiten afirmar que el extracto enzimático obtenido por maceración de cuajos de llama lactantes poseen una concentración enzimática muy superior a la de los productos comercializados. De acuerdo a las evaluaciones efectuadas el cuajo de llama presenta mayor poder coagulante, que aquellos similares empleados en la industria.

\section{Dairy Sci. 63:25-31.}

Payens T.A.J., 1976. Some features on the asociation of BCasein on the enzyme triggered clothing of casein: a preliminary account. Netherlannds Milk Dairy J. 30:55/

Payens T.A.J. and Nijhuis H., 1973. Complex formation between $\propto$-and B-casein, Netherlands Milk Dairy. 27:188.

Salabi S. and Fox P., 1982. Influence of pH on the rennet coagulation of milk. J. Dairy Res. 49,153-157.

Waisgood H. and Brunner J., 1962. Characterization of kcasein obtained by fractionation with trichloroacetic acid in a concentrated urea solution. J. Dairy \&i. 45.

Whitaker J.R., 1972. Principles of Enzymology for the food Sciences. USA. 